\title{
Perineal Ectopic Fibroadenoma
}

National Cancer Institute

\section{Source}

National Cancer Institute. Perineal Ectopic Fibroadenoma. NCI Thesaurus. Code C139547.

A benign epithelial-stromal neoplasm that arises from the perineum and resembles the breast fibroadenoma. 